\title{
Kşanti Kılguluk Nom Bitig’e Özgü İkilemeler
}

\section{Specific Hendiadyses in Ksanti Kilguluk Nom Bitig}

\author{
Mehmet ÖLMEZ ${ }^{\circledR}$, Simge SEVIM² ${ }^{\circledR}$
}

1 Mehmet Ölmez (Prof. Dr.),

İstanbul Üniversitesi, Edebiyat Fakültesi, Çağdaş Türk Lehçeleri ve Edebiyatları, İstanbul, Türkiye ORCID. 0000-0001-6422-954X

${ }^{2}$ Sorumlu yazar/Corresponding author: Simge Sevim (Yüksek Lisans Öğrencisi), Yıldız Teknik Üniversitesi, Sosyal Bilimler

Enstitüsü, Türk Dili ve Edebiyatı Ana Bilim Dalı, İstanbul, Türkiye

E-posta: simgesevim@yahoo.com

ORCID: 0000-0003-4935-8575

Başvuru/Submitted: 22.04 .2019 Revizyon Talebi/Revision Requested: 02.09.2019

Son Revizyon/Last Revision Received: 27.09.2019

Kabul/Accepted: 01.10 .2019

Online Yayın/Published Online: 17.12.2019

Atıf/Citation: Olmez, Mehmet ve Sevim Simge. "Kșanti Kılguluk Nom Bitig'e Özgü İilemeler." Türkiyat Mecmuası-Journal of Turkology 29, 2 (2019): 499-524.

https://doi.org/10.26650/iuturkiyat.660581

\section{öz}

İkilemeler, Türkçenin her döneminde olduğu gibi Eski Uygurca döneminde de görülen önemli bir anlatım özelliğidir. Araştırmacılar tarafından birçok çalışmada farklı yönleri ile ele alınan ikilemeler, Türkoloji sahasında hâlâ çalışılması ve aydınlatılması gereken konularından biridir. Eski Uygurcada çok sık kullanılan ikilemelerin tespiti ise bu metinlerin anlaşılabilirliği ve tamiri açısından fazlasılyla önem teşkil etmektedir. Bu çalışmada Kşanti Kılguluk Nom Bitig adlı eserde görülen fakat diğer Uygurca ikileme çalışmalarında yer almayan örnekler tespit edilmiştir. İkilemeler bakımından zengin bir malzemeye sahip olan bu eser, Budist Uygur edebiyatına ait bir tövbe metnidir. Makalenin giriş bölümünde; bu eser üzerine yapılan çalışmalar hakkında kısa bir bilgi verilmiş, ayrıca ikileme örnekleri hakkında bazı özelliklere değinilmiştir. Örnekler Türkçe ve Almanca karşılıkları verilerek liste halinde düzenlenmiştir. Bundan başka ikilemelerin geçtiği bağlama yer verilmiş, kullanım sıklı̆ı gösterilmiştir.

Anahtar kelimeler: Eski Uygurca, Kşanti Kılguluk Nom Bitig, ikilemeler, kelime koşmaları, Uygurca ikilemeler

\section{ABSTRACT}

Hendiadyses, seen in Old Uighur as in any other era of Turkic, are a great variance of expression. The topic of hendiadys, studied by researchers from various aspects, is still there waiting for to be examined and clarified. The hendiadyses used in Old Uighur need to be specified because of their great importance for understanding the texts written in the language. Examples that were not part of the other Uighur hendiadys studies, but seen in Kşanti Kılguluk Nom Bitig, are studied here. This work, Kşanti Kılguluk Nom Bitig, having great significance in terms of hendiadys use, is a repentance text of Buddhist Uighurs. In the introduction, a brief summary of the studies done on this work has been given. Furthermore, some points about hendiadys examples have been mentioned. Examples are listed with their Turkish and German meanings. Also, the context in which they were used and how frequently they were encountered is also given. Keywords: Old Uigur, hendiadyses, Ksanti Kılguluk Nom Bitig, word pairs, Uigur hendiadys 


\section{EXTENDED ABSTRACT}

The use of hendiadys, encountered in every Turkic work even from the first written ones, is a significant way of expression strengthening, glamourizing and harmonising phrases. As Aydemir mentioned, a few examples of hendiadyses were firstly encountered in Pott's work, who is a linguist; however, the first detailed study on the topic was done by Karl Foy. Saadet Çağatay in Uygurca'da Hendiadyoinler, presented a detailed research on especially the hendiadyses seen in Old Uighur; trying to clarify the phonetic, grammatical and semantic aspects of the hendiadyses. There will not be any mention of the other studies on the topic, but to be informed, Eski Uygurca İkilemeler by Mehmet Ölmez can be checked.

Kşanti Kılguluk Nom Bitig, a repentance text of Buddhist Uighur Literature, is a translation of a Chinese work Cíbēi dàochăng chànfă, which is composed of 40 chapters. Written for redemption through repentance and to be recited in a ritual, it was copied lots of times. Mentioned first in the $2^{\text {nd }}$ volume of Berliner Turfantexte, its whole text (1368 lines), translation, explanation and facsimile was published by Klaus Röhborn. Ingrid Warnke wrote a $\mathrm{PhD}$ thesis on the topic in 1978. In the introduction, information about the content of the text, orthography characteristics, its phonetic, morphological and syntactic value, its vocabulary and the translation method were given. Following, there is 852-line text, German translation and notes. Finally, Jens Wilkens, gathered all of the fragments in Germany, Russia, China and Japan in the $25^{\text {th }}$ book of the Berliner Turfantexte and published a 4443-line text. The first volume of this two-volume study includes Chinese and Sanskrit counterparts of the names of Buddha, text and its translation. In the second volume, there is a dictionary, facsimiles and transliteration of fragments. By analysing the BT 25, the final work on Kşanti Kllguluk Nom Bitig, the hendiadyses, which had not been included yet in earlier Uighur hendiadys researches, were studied in this article. To find out different hendiadyses, the hendiadyses in question were compared with the ones in Uygurca'da Hendiadyoinler, Eski Uygur Türkçesinde Íkilemeler and Eski Uygurcada İkilemeler Üzerine, and UW, UW NB I.1, UW NB II.1, UW NB II.2, OTWF, ED, DTS dictionaries alongside with the dictionary section of Altun Yaruk III. Kitap (=5. Bölüm), Eski Uygurca Din Dışı Metinlerin Karşılaştırmalı Söz Varlığı and Daśakarmapathāvadānamālā were utilised. The hendiadyses are listed with their Turkish and German meaning, the context they have been used, line number and written frequency. Most of the German translations are based on Wilken's translations but some has been changed in accordance with TDKAlmT. The signs that were used to indicate reduced, completed or missing parts are not included due to clarity purposes. Forms like $d t$ and $z$, which show distinct spelling features in the transcription of the text, are not benefitted also. (...) is used if there is a long or completed sentence, and to clear up what is the context, whether the sentence is in harmony or not has been looked into.

The hendiadyses, which can be seen since the very first written sources of Turkic, especially in the Old Uighur period, are mentioned in the above studies. However, 201 new hendiadyses 
in the BT 25, the most recent work on Kşanti Kılguluk Nom Bitig, are not encountered in those studies. Those 201 hendiadyses are listed, their Turkish and German translations and example sentencesand their written frequencies are given in this study. The hendiadyses, important for understanding the Old Uighur texts and rebuilding them, are presented for the attention of those who study in this field. 


\section{Giriş}

Türkçenin ilk yazılı eserlerinden itibaren görülen, anlatımı güçlendiren, güzelleştiren ve ahenklendiren ikilemeler; eş anlamlı, yakın anlamlı yahut zıt anlamlı sözcüklerin art arda gelip kalıplaşmasıyla oluşan önemli bir anlatım özelliğidir. Aydemir'in değindiği gibi ${ }^{1}$ Türkçe ikileme örnekleri ilk kez, bir dil bilimci olan Pott'un eserinde ${ }^{2}$ çok az sayıda görülmekle birlikte, bu örnekler esasıyla yinelemelere dayanır; ikilemeler üzerine detaylı ilk çalışma Karl Foy $^{3}$ tarafından yapılmıştır. Özellikle Eski Uygurca metinlerde çok sık görülen ikilemeler üzerine ise ilk olarak Saadet Çağatay Uygurca'da Hendiadyoinler ${ }^{4}$ adlı makalesinde ayrıntılı bir inceleme yapmış; fonetik, gramer ve anlam yönünden özelliklerini aydınlatmaya çalışmış ve 259 ikilemenin çevirisini, bağlamını ve geçtiği metinleri açıklayarak sunmuştur. İlerleyen yıllarda araştırmacılar bu konu üzerine daha fazla eğilmiş ve Türkçe ikilemeler üzerine birçok çalışma yapmışlar; ikilemelerin özelliklerini, oluşum kurallarını, neden ve nasıl kullanıldıklarını incelemişlerdir. Bu makalede ikilemelerle ilgili diğer çalışmalara yer verilmeyecektir; ayrıntılar için TDAY Belleten' in 2017 yılı 2. sayısında Mehmet Ölmez tarafından yayınlanan Eski Uygurca Íkilemeler Üzerine ${ }^{5}$ adlı makaleye bak1labilir.

Budist Uygur edebiyatına ait tövbe metni olan Kşanti Kılguluk Nom Bitig, 40 bölümden oluşan apokryphe (uydurma) bir Çince Budist eseri olan Cíbēi dàochăng chànfă' dan çevrilmiştir. Tövbe yoluyla günahlardan arınmak için yazılan ve bir ritüel sırasında okunan eser Uygurlarca birçok kez kopya edilmiştir ${ }^{6}$. İlk olarak Berliner Turfantexte serisinin 2. cildinde ele alınan eser; Klaus Röhrborn tarafından 1368 satır metin, çeviri, açıklama, dizin ve tıpkıbasım olarak neşredilmiştir ${ }^{7} .1978$ yılında Ingrid Warnke eserle ilgili bir doktora tezi hazırlamıştır ${ }^{8}$. Bu çalışmanın giriş bölümünde eser hakkında içerik, fragmanlar hakkında bilgi, yazım özellikleri, fonetik, morfoloji ve sentaks, kelime dağarcığı, çeviri tekniği konularında bilgi verilmiştir. Devamında 852 satırlık metin, Almanca çeviri ve notlar bulunmaktadır. Warnke 1983 yılında ise "Fragmente des 25. und 26. Kapitels des Kšanti qülyuluq nom bitig” adlı makalesinde

1 Hakan Aydemir, Untersuchung zum Wortschatz der alttürkischen Xuanzang-Biographie (mit besonderer Berücksichtigung von Buch IX), (Yayımlanmamış Yüksek Lisans tezi, Universität Göttingen, 2013), 4.

2 A. F. Pott, Doppelung (Reduplikation, Gemination) als eines der wichtigsten Bildungsmittel der Sprache: beleuchtet aus Sprachen aller Welttheile (Lemgo Germany: Im Verlage der Meyer'schen Hofbuchhandlung, 1862), 10.

3 Karl Foy, "Studien zur Osmanischen Syntax, das Hendiadyoin und die Wortfolge "ana baba", Mitteilungen des Seminars für Orientalische Sprachen içinde 2/2 (1899), 105-136.

4 Saadet Çağatay, "Uygurcada Hendiadyoinler", Dil ve Tarih-Coğrafya Fakültesi Ylllık Çalışmalar Dergisi 1 (1944), 97-144. Türk Lehçeleri Üzerine Denemeler, (Ankara, 1978) tekrar yayımlanmıştır.

5 Mehmet Ölmez, "Eski Uygurca İkilemeler Üzerine”, Türk Dili Araştırmaları Ylllığı-Belleten 65/ 2 (2017), 243-311.

6 Jens Wilkens, Das Buch von der Sündentilgung. Edition des alttürkisch-buddhistischen Kšanti Kllguluk Nom Bitig (Cilt I-II) (Turnhout, Belgium: Brepols Publishers, 2007).

7 Klaus Röhrborn, Eine uigurische Totenmesse. Text, Übersetzung, Kommentar (Berlin: Akademie Verlag, 1971).

8 Ingrid Warnke, Eine buddhistische Lehrschrift über das Bekennen der Sünden, Fragmente der uigurischen Version des Cibei-daochang-chanfa (Basılmamış Doktora tezi, Berlin Bilimler Akademisi, 1978). 
120 satır metni; çeviri, açıklama ve tıpkıbasım olarak incelemiştir ${ }^{9}$ Son olarak Jens Wilkens Berliner Turfantexte serisinin 25. kitabında Almanya, Rusya, Çin ve Japonya'dan tespit edilen bütün fragmanları bir araya getirmiş ve 4443 satırlık bir metni yayınlamışıır ${ }^{10}$. İki ciltten oluşan bu çalışmanın birinci cildinde; giriş, metinde geçen Buda'nın isimlerinin Çince ve Sanskritçe karşılıklarının listesi, metin ve çeviri yer almaktadır. İkinci cildinde ise sözlük, fragmanların transliterasyonu ve tıpkıbasımları bulunmaktadır.

Bu makalede, Kşanti Kılguluk Nom Bitig üzerine son çalışma olan BT 25 incelenerek daha önce yapılan Uygurca ikileme çalışmalarında yer almamış ikilemeler tespit edilmiştir. Farklı ikilemelerin tespiti için öncelikle bulunan ikilemeler Uygurca'da Hendiadyoinler ${ }^{11}$, Eski Uygur Türkçesinde İkilemeler ${ }^{12}$ ve Eski Uygurcada İkilemeler Üzerine ${ }^{13}$ çalışmaları ile karşılaştırılmış, anlamlandırma için UW, UW NB I.1, UW NB II.1, UW NB II.2, OTWF, ED, DTS eserleri ile Altun Yaruk III. Kitap (=5. Bölüm) ${ }^{14}$, Eski Uygurca Din Dışı Metinlerin Karşılaştırmalı Söz Varlı̆̆g ${ }^{15}$ ve Daśakarmapathāvadānamālā ${ }^{16}$ adlı çalışmaların sözlük bölümleri kullanılmıştır. İkilemeler; Türkçe ve Almanca karşılığı, yer aldığı bağlam, satır numarası ve görülme sıklığıyla birlikte listede yer almıştır. İkilemelerin Almanca karşılıklarında çoğunlukla Wilkens'in çevirisine sadık kalmakla birlikte bazı çeviriler anlama ve TDKAlmT'ye uygun olarak değiştirilmiştir. Metinlerin anlaşılır olması amacıyla eksik, tamamlanan veya düşen kısımları göstermek için kullanılan işaretler eklenmemiştir. Transkripsiyon sisteminde yer alan, metinlerin imla özelliğini gösteren $d \underline{t} t$ ve $z$ gibi şekiller kullanılmamıştır. İkilemenin geçtiği bağlam alınırken anlaşılır bir bütün olmasına dikkat edilmiş, eksik veya tamamlanan kısım varsa yahut çok uzun bir cümle ise (...) ile tamamlanmıştır.

İkilemeler genelde iki unsurdan oluşmakla birlikte üç unsurdan oluşanlar da mevcuttur. Örneğin; ezüg çınsız yarpsız "yalan, sahte, gerçekdışı” (BT 25: 0381-0382), buş- sıkıl-tałıl"sıkışmak, sıkılmak, daralmak" (BT 25: 0565), tokl- tọla- kına- "dövmek, kamçılamak ve cezalandırmak” (BT 25: 1047), yèg üstünki edgülüg “çok iyi ve sağlıklı” (BT 25: 3720). İkilemelerden uulsuz/ulsuz tüpsüz alkınçsız tüketinçsiz ise benzer anlamda olan iki ikilemenin sıralanmasıyla oluşan sıralı ikilemedir.

Bazı ikilemelerde ikileme içinde ikileme görülmektedir. Örneğin; kal teltök bol-yayıl"şaşırmak ve yanılmak" (BT 25: 2806-2807) ikilemesinde ilk unsur olan kal teltök bol- içinde kal teltök "deli, kaçık" ikilemesi; ters azag nomlug tirtè "sapkın, kafïr" (BT 25: 2824-2825)

9 Ingrid Warnke, "Fragmente des 25. und 26. Kapitels des Kšanti qïlyuluq nom bitig", Altorientalische Forschungen, 10(1-2), (1983): 243-268.

10 Wilkens, Das Buch von der Sündentilgung. Edition des alttürkisch-buddhistischen Kšanti Kllguluk Nom Bitig (Cilt I-II).

11 Çağatay, "Uygurcada Hendiadyoinler", 97-144.

12 Serkan Şen, Eski Uygur Türkçesinde İkilemeler (Yayımlanmamış Yüksek Lisans Tezi, Ondokuz Mayıs Üniversitesi, 2002).

13 Mehmet Ölmez, "Eski Uygurca İkilemeler Üzerine,” 243-311.

14 Mehmet Ölmez, Altun Yaruk III. Kitap (= 5. Bölüm) (Ankara: TDAD 1, 1991).

15 Özlem Ayazlı, Eski Uygurca Din Dışı Metinlerin Karşılaştırmalı Söz Varlığl (Ankara: Türk Dil Kurumu, 2016).

16 Murat Elmalı, Daśakarmapathāvadānamālā, Giriş-Metin-Çeviri-Notlar-Dizin Tıpkıbaskı (Ankara: Türk Dil Kurumu Yayınlar1, 2016). 
ikilemesinin ilk unsuru ters azag nomlug içinde ise ters azag “yanlış, sapkın” ikilemesi vardır.

Metinde tespit edilen iki örnekte ise ikinci unsurların satırın üstüne sonradan eklendiği görülmüştür. Örneğin; uzatı kişilerig ütlep eriglep katıglanturup ((tavranturup)) (BT 25: 3966)

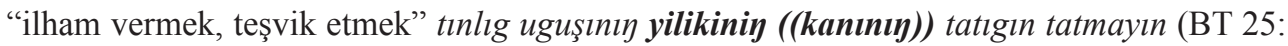
3704) “ilik ve kan”. Bu durum ikileme unsurlarının birbirinden ayrılmadığını kanıtlar niteliktedir.

İnceleme sırasında tespit edilen bazı ikilemeler tamamlama yapılmıştır. Tamamlanan ikilemelerin çoğu listeye dâhil edilmemiş fakat bu bölümde belirtilmesi uygun görülmüştür.

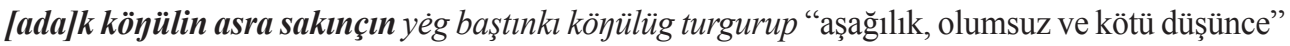
(BT 25: 0325) [1 kez], köyülin köküzin amırtgurup t/urulturup] "yatıştırmak, teselli etmek, durultmak" (BT 25: 1691) [1 kez], armaksız/ın sönmeksizin ] "yorulmadan, durmadan" (BT 25: 0956-0957) [1 kez], (...) [erig/lep ütlep (...) "öğüt vermek, uyarmak, ders vermek” (BT 25: 1868-1869) [1 kez], “yılkı tégli [er]mez yavız yollarta tugup “olumsuz ve kötü” (BT 25: 0312) [1 kez], [bagsı]z çugsız atlıg tẹri burhan kutına yükünürmen bek "bağsız, kösteksiz" (BT 25: 1787) [1 kez], alku ugrın birikzün ya[kzun] "birleşmek, yaklaşmak” (BT 25: 1134) [1 kez], (...) [bütmek]i kanmakı bolzun "tatmin olma, kanma" (BT 25: 4426) [1 kez], yoğun érig savlar üze èr[e ayıglayu] "yermek, kötülemek, hakaret etmek" (BT 25: 0309) [3 kez], agulug emgetmeklig köyülüm üze birer k[or] kem kelmiş sayu yalar oot teg "zarar, hasar ve hastalık" (BT 25: 0068) [1 kez], bo nom erdinig boşgundaçı tutdaçı okıtaçı [okıtdaçı] “okumak ve okutmak" (BT 25: 0015-0016) [1 kez], (...) tit]diükde ertdük/de (...) “terk etmek, vazgeçmek, geçmek” (BT 25: 0909) [1 kez], y[ü]kü[nürbiz tuyunmış odunmış] atlıg tẹri burhan kutına "uyanmış, aydınlanmış" (BT 25: 1985) [1 kez], ne üçün tèse [r tüp tüz adırtsız] köyülin “dümdüz, ayrımsız” (BT 25: 3377-3378) [1 kez], nom [la]rı unıtmadaçı [titmedeçi] bolayın "unutmak ve vazgeçmek" (BT 25: 4031) [1 kez], birerde agızınta oot yalını ü[nüp tulup] “çıkmak, dişarı vurmak" (BT 25: 0760) [1 kez], üz b[oz öç] kek köyülüg şeşmek yörmek (...) "kin, nefret, öç” (BT 25: 1526) [1 kez], alku üzlüg [bozlug öçlüg keklig köyülümüz] ni kèterü tarkaru "kinli, öfkeli, nefret dolu" (BT 25: 1645-1646) [1 kez], öz öz térinleriniך kuvraglarınıy yarukları yaşukları yaruyu yaşuyu ü/stelü (...) "parlamak ve çoğalmak" (BT 25: 1798) [1 kez], etözüg köyül[üg yumak] arıtmaklıg bürtmek[lerig] özin uzatı bürteyin “yıkama, aritma" (BT 25: 3773) [1 kez].

Tamamlanan ikilemelerde; sadece birkaç harf tamamlama ise ve kelimenin ne olduğu açıkça anlaşılıyorsa listeye alınmıştır. Örneğin; [ö]lütçi yititçi "katil” (BT 25: 0528) [1 kez], samantabadre puik[en] "Buda'nın sağ kolu, temel kanunların efendisi” (BT 25: 1317) [2 kez], tugm[aklıg] ölmek[lig] “doğum ölüm, samsara” (BT 25:1072) [2 kez].

bir kün ıdok ordosinta aroklap yatur erken "dinlenmek, yatmak" (BT 25: 0046) [2 kez], busuşlug emgekligin tegürü èltip "ulaştırmak, götürmek; refakat etmek" (BT 25: 0585) [1 kez] ve bo közünür üdte yene tugguluk kurug asıgsız kemişü ıdıp "reddetmek, vazgeçmek" (BT 25: 0651) [1 kez] kelime grupları ise her bir unsur cümle içinde farklı ulaç eki aldığı için listeye dahil edilmemiştir. 
Metinde ikilemeyi andıran ilkisiz uzun "başlangıcı olmayan ve uzun" (BT 25: 0688), baş otra adak "baş, orta, ayak" (BT 25:0254), etöz til köyül "vücut, dil ve gönül” (BT 25: 0464), öydünki kédinki küntünki tagtınkl "doğudaki, batıdaki, güneydeki, kuzeydeki” (BT 25: 27022703), şikşamane şarmire şarmaranç “öğrenci, erkek mürit ve kadın müritler” (BT 25: 1941) gibi kelime grupları, aynı kavram alanından kelimelerin örnek olarak sıralanmasıyla oluştuğu için ikileme olarak alınmamıştır. ayı ked "çok" (BT 25: 1048) [1 kez] ikilemesi için ise kararsız kalınmış fakat UW NB II.2'de ikileme olarak gösterildiği için listeye dâhil edilmiştir. ${ }^{17}$

Tespit edilen ikilemelerin çoğunluğu metinde bir kez geçmiş olup en çok rastlanan ikilemeler ise köyülçe tapça "arzuyla ve istekle" (BT 25: 0647) [10 kez] ve edgü ögli ayıg ögli“ iyi ve kötü kalpli" (BT 25: 0254-0255) [9 kez] ikilemeleridir. katıg çike "katı ve sert" (BT 25: 0400) [1 kez] ikilemesinde ise çike kelimesine ilk kez bu metinde rastlanmıştır.

\section{İkilemeler}

aç saran "açgözlü ve cimri / gierig und geizig"

aç saran köyülüg titü umadın (BT 25: 0768) [ $1 \mathrm{kez}$ ]

açın- todgur- "beslemek, doyurmak / versorgen und sättigen"

yene yılkı ajunınta tüştüklerinte edgü yėzgü üze açını todgurup (BT 25: 2157) [1 kez]

açmak usmak "açlik ve susuzluk / Hunger und Durstigsein"

prètlarnıı açmak usmak (...) üze çulup buşrulup (BT 25: 3568) [3 kez]

adalıg kadag "tehlikeli ve günahkâr / Gefährdung und Sündhaft" adalıgın kadagın köyülin uzatı bilelim (BT 25: 3828) [1 kez]

adınsıg karşı "başka, karşı, aksi, ters / Gegenteiliges" tınlıglar bodisatavlarnı̀ yarlıgınça èyin bolup adınsıg karşı (...) (BT 25: 4178) [1 kez]

agıt- yitür-18 "(gönlünü) çevirmek ve kaybetmek / aufgeben und verlieren" bo kèrtgünç könülümni agıtmayın yitürmeyin (BT 25: 0358) [1 kez]

agrıg sızlag "ağrı sızı / Schmerz"

yip ışı tartar teg agrıg sızlag yorıuur (BT 25: 0566) [1 kez]

17 Klaus Röhrborn, Uigurisches Wörterbuch. Sprachmaterial der vorislamischen türkischen Texte aus Zentralasien, Neubearbeitung - II. Nomina-Pronomina-Partikeln. Band 2: aş - äžük. (Stuttgart: Franz Steiner Verlag, 2017$) 81$.

18 BT 25 (Wilkens, 2007:74) ve UW NB I.1'de (Röhrborn, 2010:24) ètür- olarak okunan kelime yitür- olarak değiştirilmiştir. 
akıltur- yad- "akıtmak ve yaymak / ausströmen lassen und verbreiten (Vighuștaśtrī: Buddhaname)" yükünürmen edgüsin edremin akılturdaçı yadtaçı atlıg tejri burhan kutı̇a (BT 25:1785) [1 kez]

alkugun barça kalısız "bütün, tamamen, hepsi / alle insgesamt, restlos" alkugun barça kalısız öçzünler arızunlar (BT 25: 0861) [1 kez]

amra- sakın- "sevmek ve düşünmek / lieben und denken"

kamag ulug bodisatavlarnıџ tınlıglarıg amramakı sakınmakı ögnüy kaynınta artok erür tèp (BT 25: 0302) [1 kez]

amtı tėmin "şimdi, demin / jetzt sogleich"

amtı témin yayırtı tuyunup odunup (BT 25: 0852) [1 kez]

anuk bar "hazır, var / bereit" tamuta barçaka bo ayıg kılınçlıg ülüş anuk bar erür (BT 25: 2203-2204) [1 kez]

apıt- yupat- "gizlenmek, saklanmak / (sich) verbergen" kentü özin apıtu yupatu umadın (BT 25: 0053) [1 kez]

ar- emgen- "yorulmak ve zahmet çekmek / müde sein und müde abplagen" sézik köyül öritip ardım emgentim tèp tèyü yarlıkamazunlar (BT 25: 0633) [1 kez]

ar- ermegür- "yorulmak / müde sein" yene artokrak arıp ermegürüp (BT 25: 0842) [1 kez]

artamak ertmek "yok olma, ölme, geçip gitme / Vergehen" terk tavrak ürlüksüz törö èyin artamak ertmekke kelip (BT 25: 0579) [1 kez]

artat- sı- "(dini emir ve yasaklar için) bozmak ve kırmak / (Gebote) verletzen und brechen" üç törlüg (...) artatmadın sımadın (BT 25: 4008) [1 kez]

artok üküş "çok, fazla / mehr" belgürtmelerte artok üküş kalp sakışı üze (BT 25: 2141) [1 kez]

asankẻ nayut "sayısız, sayılamayacak kadar çok / unzähligen" asanke nayut sanınça tınlıglar (BT 25: 0034) [2 kez] 
av- kel- "kuşatmak; etrafına toplanmak, birikmek / wimmeln" telim üküş kurtlar avıp kelip (BT 25: 0077) [1 kez]

avant tüş "sebep ve sonuç / Ursache und Wirkung" yme bo avant tüş tözlüg nomlarnıり kölige teg yajku teg erdüki üze (...) (BT 25: 0511) [1 kez]

ayı ked "çok / sehr" açıg emgekin ayı ked emgen- (...) (BT 25: 1048) [1 kez]

ayıg kılınç buyan "günah ve sevap / Sünde und Verdienst" yme bo ayıg kılınçlı buyanlınıy avantınıๆ tüşiniๆ tugruşmakları üze (BT 25: 2872) [2 kez]

azkıya yukakıya "azıcık, küçücük / ganz klein und gering" edgü ögli köyüli olarnı üze azkıya yukakıya bolur (BT 25: 0295) [1 kez]

azlan- yapşın- "imrenmek, yapışmak / begehren und haften" negülük ol maya bo çöpik yavız üdke koluka azlanıp yapşsnıp (BT 25: 0642) [1 kez]

bar- teg- "varmak, ulaşmak / hingehen und ankommen" öz sakınçın ol kişilerke barıp tegip (BT 25: 1190) [1 kez]

boşgutlug boşgutsuz "eğitim gören kişi ve artık eğitime ihtiyacı olmayan kişi, öğrenci ve usta / mit Belehrung (Skt. śaikșa) = Schüler und ohne Belehrung (Skt. aśaikșa) = Meister" boşgutlug boşgutsuz toyınlarnıy edgülüg edremlig yıdların uzatı yıdlalım (BT 25: 3657-3658) [1 kez]

busuşlug emgeklig “sıkıntı, keder, üzüntü / Kummer und Schmerz” busuşlug emgekligin tegürü èltip (BT 25: 0585) [1 kez]

buş- sıkıl- tạıl- "sıkışmak, sıkılmak, daralmak / sich bedrängt fühlen” tın buşup sıkılıp tayılıp (BT 25: 0565) [1 kez]

büt- tüket- "bitmek, tüketmek / sich erfüllen und beenden" iki sakınçı. büte tüketser (BT 25: 1170) [6 kez] 
çıgay emgeklig "fakir ve sıkıntılı, dertli / arm und leidend"

çıgay emgeklig bolmışları közünür (BT 25: 0530-0531) [1 kez]

çınsız kẻrtüsüz "yalan yanlış / unwahre"

tokuzunç kayu sözlegülük savlarda çınsız kèrtüsüz savlıg bolmak

(BT 25: 2193-2194) [1 kez]

çinle- bışgur- "(yemek) pişirmek / dünsten, kochen”

tıłlıglarıg çiylemiş bışgurmış (...) sögülmiş yıdlarıg yıdlamalım (BT 25: 3632) [1 kez]

çuך koyragu "çan, zil, çıngırak / Glocke, Schelle"

çuy koyragu labay kövrüg kim sır (...) (BT 25: 3583-3584) [1 kez]

edgü asıglıg "iyi, faydalı, yararlı / Der mit gutem Nutzen"

yükünürbiz edgü asıglıg atlı teyri burhan kutına (BT 25: 2459) [1 kez]

edgü ögli ayıg ögli "iyi ve kötü kalpli / Gute und Böse"

başta otra adakta olurdaçı edgü ögli ayıg ögliler üçün (BT 25: 0254-0255) [9 kez]

elvir- ${ }^{19}$ buş- "(aklı) karışmak, delirmek / verwirrt sein"

ögi biligi elvirip buşup (BT 25: 2941) [1 kez]

emgek sıkıg "dert, sikıntı / Leid, Not"

emgekke sıkıgka teggülük erip inçip (BT 25: 0532) [2 kez]

emgen- katıglan- "acı çekmek ve gayret etmek / sich plagen und anstrengen"

altı kırkınç emgendeçi katıglandaçı edgülük işlerke èyin ögirdeçi küç bèrdeçiler

(BT 25: 3039-3040) [2 kez]

emgen- sıkıl- "eziyet çekmek, sıkılmak / leiden"

körü tükettükte emgenip sıkılıp (BT 25: 0412) [1 kez]

emget- sık- "eziyet veren, yaralayıcı / verletzend"

olar neçe katıg çike emgetteçi sıkdaçı savlarıg sözleser (BT 25: 0400) [1 kez]

19 BT 25'te (Wilkens, 2007:232) alvir- olarak yer alan kelime UW NB I.1'e (Röhrborn, 2010:54, 134) göre elvirolarak değiştirilniştir. 
emgetiş- tokış- "karşıl1klı eziyet vermek ve dövüşmek / sich gegenseitig quälen und schlagen" birtemleti yene altı yollarta açıg tarka emgekler üze emgetişmezünler tokışmazunlar (BT 25: 1599-1600) [1 kez]

et teri "et ve deri / Fleisch und Haut"

telim üküs kurtlar avıp kelip etimin terimin isirmekleri sormakları üze

(BT 25: 0077) [1 kez]

etöz et "vücut ve et / Körper und Fleisch"

olarnıy etözlerin etlerin (...) (BT 25: 3494) [1 kez]

etöz körk "vücut, beden, görünüş, şekil / Körper und Gestalt"

meniy bo etözümin körkümin tuta (BT 25: 0781-0782) [1 kez]

etöz isig öz "vücut, canlı / Körper, Leben"

bo etözüg isig özüg titip ıdalap (BT 25: 0349) [2 kez]

evdi- al- "toplamak, almak; karşılaştırmak / sammeln lassen, annehmen" ulug agllık nomlarda evdip alıp bütürmiş (BT 25: 1517) [4 kez]

evdit- yıgtur- "toplatmak, yı̆̆dırmak / sammeln lassen"

tolp taitsoki ulug agılıg nomta evditip yıgturup yaratdurmış kılturmış erür

(BT 25: 0030) [1 kez]

ezüg çınsız yarpsız "yalan, sahte, gerçek dişı / falsch und unwirklich"

tınlıglı idişli yèrtinçüler yme ezüg çınsız yarpsız erürler

(BT 25: 0381-0382) [1 kez]

${ }^{20}$ èrig yogun "kaba / grob"

érig yogun kalvag yèp etözine tẹlep (BT 25: 0592) [1 kez]

èrinçket- tsuyurkat- "pişman olmak, üzüntü duymak / bereuen"

eๆitü yükünü érinçketü tsuyurkatu ökünü bilinü teginürbiz

(BT 25: 1084-1085) [1 kez]

èrmek ayıglamak "yerme, kötüleme, hakaret etme / Beleidigung, Schmähung" barça yavız köyülin adınlarnıy edgüsin èrmek ayıglamak ugrınta tètir (BT 25: 0851) [1 kez]

20 BT 25 (Wilkens, 2007:90) ve OTWF'de (Erdal, 1991:200) eyrig, diğer çalışmalarda irig olarak okunan kelime; UW NB II. 2 göz önüne alınarak (Röhrborn, 2017:352) érig olarak değiştirilmiştir.. 
ès- tit- "azaltmak, vazgeçmek / reduzieren und aufgeben" edgülüg yıltızların ésmezler titmezler (BT 25: 3394) [1 kez]

ıçan- saklan- "dikkatli olmak / sich hüten"

inçip bo munı teg yejg kudıkı bolguluk savlarka érteken ıçanıp saklanıp (BT 25: 2168) [1 kez]

Id- kemiş- "vazgeçmek ve reddetmek / aufgeben und verwerfen" tüşin ıdıp kemişip (BT 25: 0613) [1 kez]

Inan- yükün- "inanmak, secde etmek, ululamak / Zuflucht nehmen und sich verneigen" alku kamag tınlıglar üçün ınanu yükünü teginürbiz (BT 25: 0263) [3 kez]

Ir takşut "şarkı / Gesang”"

ır takşut ünlerig eşidtürürler (BT 25: 1453) [1 kez]

içger- tut- "benimsemek, içselleştirmek, kabullenmek / sich annehmen" ilinmeksiz yapşınmaksız könülin terinde teriy nomka kirip alkunı içgerip tutup (BT 25: 3419) [1 kez]

iglig tapsızlıg "hasta / krank" yorımak üze azkıya teĐinçe iglig tapsızlıg boltukta (BT 25: 0666) [1 kez]

ikirçü̈ sėziklig "şüpheli / zweifelnd, zweifel habend" ikirçgü sėziklig kişiler mürki biligsiz üze ataguluk bolurlar (BT 25: 0534) [1 kez]

ilinmek bodulmak "bağlanma, yapışma / Haften und Leidenschaft" burhan bahşıta ilinmek bodulmak üze (BT 25: 0433) [1 kez]

isig kuyaş "sicak ve güneş ( güneşli) / heiß und sonn" yene isig kuyaş üdlerde agır kürkde ulatı kalın tonlarıg kedtükte olarnıり emgeki busuşı teriy bolur (BT 25: 0571) [1 kez]

isirmek sormak "kemirme ve içine çekme, kuvvetle emme / Benagen und Aussaugen" etimin terimin isirmekleri sormakları üze inçe kaltı (BT 25: 0077-0078) [1 kez] 
işle- bul- "bir işi kararlılıkla yürütmek, bir şeyi çaba ile elde etmek / zu betreiben und zu erlangen" bo savlar ney öz köyülçe karışmak yarışmalaşmaklıg üze işlegülük bulguluk ermez (BT 25: 2132) [1 kez]

kal teltök esrök "deli, kaçık / verrückt”

kal teltök esrök teg bolup (BT 25: 2941) [2 kez]

kal teltök bol- yạıl- "şaşırmak ve yanılmak / irre werden und sich täuschen" burhan kutın bulgınçakategi ikileyü takı kal teltök bolup yayılıp (BT 25: 2806-2807) [1 kez]

kalısız tükel "tamamen, bütün, hepsi / restlos und gänzlich" tuyguluk nomlarıg kalısız tükel bilü yarlıkamakları üze (BT 25: 0458) [1 kez]

katıg çike "katı ve sert / hart und harsch" olar neçe katıg çike emgetteçi sıkdaçı savlarıg sözleser (BT 25: 0400) [1 kez]

katıglantur- tavrantur- "ilham vermek ve teşvik etmek / anspornen und ermutigen" uzatı kişilerig ütlep eriglep katıglanturup tavranturup (BT 25: 3966) [1 kez]

katılışmaksız bulgaşmaksız "katıksız, karışık olmayan / Unvermischt und Nichtverwirrt" katılışmaksız, bulgaşmaksız köyülüg (BT 25: 3226-3227) [1 kez]

katnayu yene "yine, tekrar, yeniden / erneut, nochmals" katnayu yene bir uçlug köyülin bėş tilgenimin yèrke tegürüp (BT 25: 1275) [1 kez]

kavışmak adrılmak "kavuşmak ve ayrılmak / Vereinigung und Trennung" kavışmakları adrılmakları tümen öyi bolur (BT 25: 0520) [2 kez]

keçmek tegmek "geçme ve ulaşma / Übersetzen und Hinübergelangen" nirvanlıg ıntın kıdıgka keçmekleri tegmekleri üçün ugrayu (BT 25: 0636) [1 kez]

kẻmi köprüg "gemi ve köprü / Schiff und Brücke" yorlguluk barguluk kèmi köprüg boltaçılar üçün (BT 25: 1289) [1 kez]

kẻjet- boşun- “(ömrü) uzatmak ve serbest olmak, kurtulmak / (das Leben) verlängern und sich befreien" netegin kentü özüm kèyetgeli boşungalı ugay biz (BT 25: 2896-2897) [1 kez] 
kėnürü aça yada "ayrıntıl1, bütünüyle, açarak, yayarak / ausführlich" kşanti kılguluk nom bitigig kèyürü aça yada okıtgu üçün (BT 25: 2059-2060) [3 kez]

kẻrtgün- tegin- "inanmak ve kabul etmek / an (etwas) glauben und es hinnehmen” asıg tuso kılu yarlıkamışların yme ök kèrtgünmedin teginmedin (BT 25: 0308) [1 kez]

kẻrtgün- umun- "inanmak ve güvenmek / glauben und vertrauen" bir uçlug köyülin kèrtgünüp umunup (BT 25: 0338-0339) [1 kez]

kèter- tarkar- "gidermek, uzaklaştırmak / beseitigen" könülümüzni kèterü tarkaru öçürü amırtguru yarlıkazunlar (BT 25: 1646) [1 kez]

kıl- belgürt- "yaratmak, üretmek ve oluşturmak / schaffen und hervorbringen" yıl sanı üze kılmış belgürtmiş (BT 25: 2140) [1 kez]

kılınç çarit "iş, fiil, icraat, davranış / Taten und Wandel" bo alku tınlıglarnıり kılınçları çaritları yintem bir teg ermez üçün (BT 25: 0515) [1 kez]

kırı luvlan "anlamsız / sinnlos" yalyuz kentü özi ök kurulup kırı luvlan erür ermez (BT 25: 0741) [1 kez]

kısur- kısga kıl- "kısaltmak / verkürzen" yaşaguluk yaşın kısurup kısga kılıp (BT 25:0394-0395) [1 kez]

ki lug tẻgme at bitig "başlık listesi, isimler listesi, kitap listesi, dini kitaplar listesi / Titelverzeichnis, Kanonkatalog und (Werk-)Titelverzeichnis" tolp taitsoki ulug agllı nomnuy ki lug tègme at bitiglerin tutdurup (BT 25: 0130) [1 kez]

korlug kunçlug "zarar, hasar / Schäden” üküş telim kişilerig korlug kunçlug kılıp (BT 25: 0069) [1 kez]

könülçe tapça "arzuyla ve istekle / nach Wunsch" savlarım barça köyülçe tapça enç esen ermişimizke (...) birök tavranmasar katıglanmasar biz (BT 25: 0647) [10 kez] 
kör- eşid- "görmek duymak / sehen und hören"

alp uguluk körmegülük eşidmegülük ülgüsüz üküş emgek tüşlüg tıltaglarlg kıltım erser (BT 25: 1077) [1 kez]

kör- sakın- "bakıp düşünmek, dikkatlice incelemek / betrachten und erwagen" muntag körü sakınu tükettükde birök olar emgek teginmiş (BT 25: 1188) [1 kez]

kudıkı asrakı "alçak, düşük / Niedrig"

kudıkı asrakı yavız yavlaklarka umug ınag bolup (BT 25: 0398-0399) [3 kez]

kurug asıgsız "faydasız, boş, nafile / nutzlos" bo közünür üdte yene tugguluk kurug asıgsız kemişü ıdıp (BT 25: 0651) [1 kez]

kut kol- küsüş örit- "şans dilemek, istekte bulunmak / Heil erflehen und den (Gelübde) wunsch wünschen"

kut kolu küsüsş öritü teginürmen (BT 25: 0237) [1 kez]

kut kolunmak küsüş küsemek “şans dileme, istekte bulunma / Heil erflehen und den (Gelübde) wunsch wünschen" kayu kut kolunmak küsüş küsemekim bodisatavlar (...) (BT 25: 1132) [1 kez]

küse- kut kolun- "istemek, kurtuluş için yalvarmak / wünschen, Heil erflehen" küseyü kut kolunu teginirmen (BT 25: 1233) [1 kez]

küsüş köĐül "istek, gönül, arzu / Wunsch" bo \{köyülümdeki\} küsüşüm köyülümtegiçe bolup (BT 25: 3699) [2 kez]

mürki biligsiz "aptal ve cahil / dumm und unwissend" ikirçgü séziklig kişiler mürki biligsiz üze ataguluk bolurlar (BT 25: 0535) [1 kez]

narakapalakẻ rakşaz “cehennem bekçisi, kötü yaratık, insan yiyen şeytani varlık / Höllenwächter und rākșasa"

narakapalakè rakşazlarnıy boşumadın kėyürü ıdmadın turmışları közünür (BT 25: 2934-2935) [1 kez]

oonguluksuz yaşguluksuz "gizlenemeyen, saklanamayan / sich nicht verbergen und können" oonguluksuz yaşguluksuzka tegip (BT 25: 0053) [1 kez] 
öçür- amırtgur- "söndürmek, yatıştırmak / auslöschen und beruhigen"

köyülümüzni kèterü tarkaru öçürü amırtguru yarlıkazunlar (BT 25: 1646) [1 kez]

öl- ert- "ölüp gitmek / sterben"

olar ölmiş ertmiş künte ötrü yene sézik köyül öritip (BT 25: 0604) [1 kez]

ölütçi yititçi" "katil / Mörder"

ölütçi yititçi kişiler kısga yaşlıg bolgu erip (BT 25: 0528) [1 kez]

öyre èrterek "önceden, eskiden / früher"

öyre èrterek ök ölgüm eryük (BT 25: 0669) [1 kez]

ördek kaz "yaban ördeği ve yaban kazı / Wildente und Wildgänse" barça ördekler kazlar belgürtüp (BT 25: 1451) [1 kez]

örit- turgur- "oluşturmak, meydana getirmek / hervorbringen" kamag edgülerig öritip turgurup (BT 25: 3418) [1 kez]

övkelig keklig “öfkeli / zornig” övkelig keklig köyüli turup (BT 25: 0293-0294) [1 kez]

rasayan tatıg "iksir / Rasāyana-Elixier" nomlug rasayan tatıgıg bolup (BT 25: 2713) [2 kez]

saç- yad- "saçmak, yaymak / verbreiten, ausbreiten" alku tınlıglarka kėyürü saçgalı yadgalı şastr nomlarıg ötgürmiş (BT 25: 0132) [1 kez]

saçok yạlok "dağınık, dikkatsiz / Zerstreut"

birök kim kayu kişiler saçok yaylok köyülin erser (BT 25: 0826) [1 kez]

samantabadre puiken "Buda'nın sağ kolu, temel kanunların efendisi / Samantabhadra" samantabadre puiken bodisatav teg nom üçün etözlerin köyürdeçi bolzunlar (BT 25: 1317) [2 kez]

seçilmiş ünmiş "seçilmiş ve yükselmiş / auszeichnet und hervorragt" beki katıgı üze seçilmiş ünmiş (BT 25: 3175) [1 kez]

21 BT 25 (Wilkens, 2007:86) ve OTWF' de (Erdal, 1991:115) yètitçi olarak okunan kelime yititçi olarak değiştirilmiştir. 
sevmek amranmak "hoşlanma, sevme / Liebes-, mit Liebe" sevmek amranmaklig (...) (BT 25: 1832) [1 kez]

sèzik sakıg "şüphe, kaygı, endişe / Zweifel”

ikinti sèzikig sakıgıg tarkarmaklıg bölök alku tınlıglar ikirçgü séziktin öyi üdrülmeyük (BT 25: 0505) [1 kez]

sėzik sakınç "şüphe ve düşünce / Zweifel und Grübelei” sézikig sakınçı yokaddurmasar biz neteg bolgay (BT 25: 0339) [1 kez]

sèzik yayılmak "şüphe ve hata / Zweifel und Irrtum" ol sézikleri yayılmakları ugrınta üç yavlak yolta tüşerler (BT 25: 0617-0618) [1 kez]

sėzin- ıçan- "sakınmak ve dikkat etmek / sich hüten und in acht nehmen" çın kèrtü sézingülük ıçanguluk bolgaylar (BT 25: 0334) [1 kez]

sık- emget- "sıkmak, eziyet etmek / quälen und peinigen" öz etözlerin sıkgu emgetgü negü erki tép sözlep (BT 25: 0596) [2 kez]

sız- öç- "erimek ve sönmek, eriyip kaybolmak / schmelzen und verlöschen" alku ayıg kılınçlıg tıdıgları barça sızıp öçüp (BT 25: 2311-2312) [1 kez]

sök-22 tuta- "sövmek, yermek, hakaret etmek / verfluchen und verächtlich machen" terkin tavratı olarnı söküp tutap (BT 25: 0772) [1 kez]

stup virhar "tapınak, manastır; Buda'ya ait eşyaların saklandığı ibadet yeri / Stūpa und Kloster” stupka virharka kirip (BT 25: 0826-0827) [1 kez]

su süt "su ve süt / Wasser und Milch" alkugun barça suvlı sütli teg tüz baz bolup (BT 25: 1602) [2 kez]

sukançıg edgü "harika ve güzel / wunderbar und gut" kamag teyrilerniך sukançı edgü ton kedimleriniy bürtüglerin uzatı bürtelim (BT 25: 3764) [1 kez]

22 BT 25'te (Wilkens, 2007:102) sög- olarak yer alan kelime OTWF'de olduğu gibi (Erdal, 1991:270) sök- olarak değiştirilmiştir. 
sukançıg körkle "sevgili, sevimli, güzel; Buda’nın isimlerinden biri / Liebliche, (Sulocana = Buddhaname)" yükünürbiz sukançı körkle közlüg atlıg teĐri burhan kutına (BT 25: 1986) [1 kez]

suvı- sıka- "yıkayıp sıvazlamak / (jemanden) baden und massieren" etözlerin tüze suvıp sıkap (BT 25: 1191) [1 kez]

şeşmek yörmek "çözüm, çare / Lösung, Auflösung”

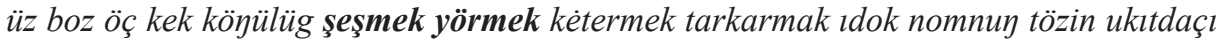
besşinç ülüş nom tükedi (BT 25: 1526) [1 kez]

taitsoki ulug agılık nom "kitap, büyük hazine, Budizm külliyatını oluşturan üç tür kitap / Das Buch, Großes Schatzhaus, scil. das Tripițaka; scil. der buddhistische Kanon" tolp taitsoki ulug agılık nomlarda evdip alıp bütürmiş (BT 25: 2035) [6 kez]

talula- altur- "seçmek / auswählen und (Schriften) heranziehen lassen" kşanti kllguluk nom bitiglerig talulap alturup (BT 25: 0134) [1 kez]

tarı- ek- "ekmek, dikmek, tohum ekmek / säen" öyre kılmış kılınçnıり tarımış ekmiş tavarnıり tüşin utlısın bilmedin (BT 25: 0537) [1 kez]

tart- ozgur- "çekmek, kurtarmak / herausziehen und retten" olarnı emgeklerintin tartıp ozgurup (BT 25: 0414) [5 kez]

tartıl- oz- "dışarı çıkarılmak ve kurtulmak / sich herausziehen und befreien" üç yavlak yollartın özin tartılgalı ozgalı (BT 25: 3454) [1 kez]

tavış tuvuş "gürültü / zischendes, Geräusch" taştırtın bir tavış tuvuş ün eşidilti (BT 25: 0047) [1 kez]

tayan- tüş- "dayanmak, destek almak / sich stützen" kayuka erser tayangusın tüşgüsin arıtı bilinmez ukunmaz (BT 25: 2925) [1 kez]

tegin- bışrun- "kabul etmek, hissetmek, farkına varmak /empfinden, (etwas geistig) kultivieren, meditativ betrachten" on törlüg tegingülük bışrunguluk dyanlarıg (BT 25: 1335) [1 kez] 
tek ançak "tek, ancak, sadece, yalnızca / nur, lediglich"

tek ançak bir kşanda bir kezde bir koluda bir muhrutta bir künte bir ayta (...)

(BT 25: 0819) [1 kez]

tegri arji " tanrı ve ermiş / Gott und Seher"

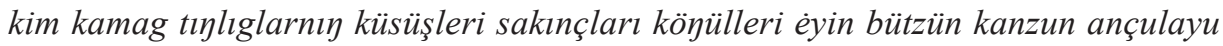
teyrilerde arjilarda (BT 25: 0491) [1 kez]

tẹsiz tüzsüz "benzersiz, eşsiz / ungleich"

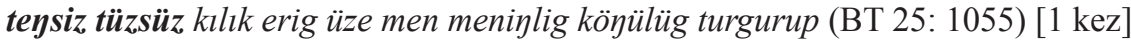

tepremek kamşamak "hareket etme, sallanma, yerinden oynama / Bewegung"

besş törlüg buyanlar üze tüzüglüg ögrünçülügin yorımak barmak tepremek kamşamak evrilmek tegzinmekte (...) (BT 25: 0646) [1 kez]

ters azag nomlug tirtė "sapkın, zındık / die Häretiker, die tīrthikas"

bek katıg köyüllerin alku şimnularka ters azag nomlug tirtèlarka buzgalı artatgalı (BT 25: 2824-2825) [2 kez]

ters nomlug tirtė "sapkın, zındık / die Häretiker, die tīrthikas" alku ters nomlug tirtèlarıg adak asra kllıp (BT 25: 1284-1285) [1 kez]

tıdıglıg adalıg "engelli, engellenmiş / Behinderungen" alku tıdıglıg adalig savlarlg turgurup (BT 25: 0735) [1 kez]

tıdıglıg köşiklig “engelli, örtülü, gizli, kapalı / hinderlich und verhüllend, mit Hemmnissen und Verhüllungen"

kayu neçe tıdıglıg köşiklig ülgüsüz üküş ayıg kılınçlarım bar ermiş erser (BT 25: 0859) [1 kez]

tıdıl- köşitil- "engellenmek, mâni olunmak / behindert werden” anın nomta üküş tıdılurlar köşitilürler (BT 25: 0507) [1 kez]

tıdıl- üzül- "engellenmek, tutulmak / behindert und abgehalten" ötrü kılınçlıg tıdıg tutug üze tıdılıp üzülüp (BT 25: 0333) [1 kez]

tın- seril- "dinlenmek, istirahat etmek, nefeslenmek / sich ausruhen" edgü nomta bışrunu ögretinü ikileyü takı ançakıya erser yme tınalım serilelim tèp tèmezünler (BT 25: 0659) [1 kez] 
tilin- tegzin- "dönüp dolaşmak / sich drehen"

burhannıり yarlıgıђa karışmak üze anın üç yavlak yolta tilinip tegzinip

(BT 25: 0680) [1 kez]

titilmez tegşilmez "vazgeçilmez ve değişmez / unaufgebbar und unveränderlich" titilmez tegşilmez ürlüklüg tėgüçi adın savlar köligeli yaykulı teg (BT 25: 2877) [1 kez]

tokı- tọla- kına- "dövmek, kamçılamak ve cezalandırmak / schlagen, peitschen und bestrafen" yene adınlarnıy etözin tokıp toylap kınap (BT 25: 1047) [1 kez]

tözün yavaş "asil ve uysal / edle und sanfte"

tözün yavaş edgü savlar (...) (BT 25: 0236) [1 kez]

tugmaklıg ölmeklig “doğum ve ölüm; doğum ölüm döngüsü, dünya / zum Geborenwerden und Sterben gehörig (Skt. saṃsāra)"

tugmaklıg ölmeklig taloyka kirdimiz erser (BT 25:1073) [2 kez]

tumlug buzlug "soğuk ve buzlu / kalte und eisige"

tumlug buzlug üdlerde inçip karzta ulatı yoğun tonlarıg kedtükte (BT 25: 0568) [1 kez]

tusola- kergekle- "yararlı ve gerekli olmak / nützlich und notwendig sein"

(...) yértinçüde belgürmişin ök tusolayu kergekleyü ermez (BT 25: 1158) [1 kez]

tut- boşgur- "tutup kavramak ve öğretmek / halten und lehren"

bo nom erdinig tutar boşgurur okıyur sözleyür erken (BT 25: 0546-0547) [1 kez]

tutmak içgermek "tutup kendine çekmek, içine almak / Umfassen und Ansichziehen" edgü ögli yarlıkançuçı könül üze tutmak içgermeklerin teginip

(BT 25: 1675) [1 kez]

tuyuntur- oduntur- "hissettirip uyandırmak, hissettirip aydınlatmak / erleuchten und wachrüttein, zur Erleuchtung bringen"

alku kamag tınlıglarıg alkunı barça tuyunturu odunturu yarlıkazunlar

(BT 25: 0487) [1 kez]

tülüklüg küçlüg küsünlüg "güçlü, kuvvetli / Macht und Kraft"

yükünürbiz ulug tülüklüg küçlüg küsünlüg atlıg bodisatav kutına (BT 25: 3545) [1 kez] 
türklüg küçlüg "kuvvetli ve güçlü / Mächtiger und Kräftiger" yükünürbiz türklüg küçlüg teĐri burhan kutına (BT 25: 3073) [1 kez]

umug urunçak "umut ve teminat / Hoffnung und Pfand" alku kamag bodisatavlarka mahasatavlarka umug urunçak tutuzu teginürbiz (BT 25: 4162) [1 kez]

umunmak kẻrtgünmeklig "güven ve inanç / zum Hoffen und Glauben gehörig, des Hoffens und Glaubens" umunmak kèrtgünmeklig nom kapıgıђa uçuz ołay kirgeli bulgay (BT 25: 0330-0331) [2 kez]

unit- Irat- "unutmak ve uzaklaştırmak / vergessen" bo küsüşüg sakınçıg unıtu ıratu yarlıkamazunlar (BT 25: 2223) [1 kez]

utlısız törösüz "nankör ve yaramaz, terbiyesiz / undankbar und unartig"

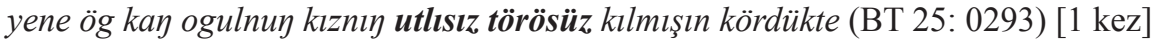

utunçsuz yẻgedinçsiz "yenilmez, mağlup edilmez / Unbesiegbarer" yükünürbiz utunçsuz yégedinçsiz atlig tegri burhan kutına (BT 25: 1913-1914) [1 kez]

uulsuz/ulsuz tüpsüz alkınçsız tüketinçsiz “dipsiz, sonsuz, tükenmez / maßlos und unendlich" uulsuz tüpsüz alkınçsız tüketinçsiz üstün kök kalıkyü̈̈zinteki (...) (BT 25: 0260) [3 kez]

uzatı menün "her zaman, daima, sonsuz / stets, auf ewig" burhan erdini kutıya uzatı meyün turdaçı alku kamag nomlarda arıg süzök tözi üze (BT 25: 0461) [1 kez]

ürtüg köşik “örtü, perde / Bedeckung und Verhüllüng” yükünürbiz ürtügüg köşiküg kemişmiş atlig bodisatav kutına (BT 25: 2537-2538) [1 kez]

ütleş- erigleş- "öğütleşmek, birbirlerine karşılıklı öğüt vermek, birbirlerini karşılıklı uyarmak / sich gegenseitig ermahnen, sich gegenseitig beraten" ulug kuvrag bökünki kün üze yintem ütleşü erigleşü (BT 25: 0657) [1 kez]

yạlok tetrülmek "yanlış, hatalı düşünce / irrige Fehleinschätzung" yaylok tetrülmekig öritürler (BT 25: 0556-0557) [1 kez] 
yalnuz birkiye "yalnız, biricik, tek / einzige(-r, -s)"

alku kamag tınlıglarıg inçe kaltı yalyuz birkiye sever amrak oğulça sakınıp (BT 25: 0276) [2 kez]

yalvar- küse- "yalvarmak, istemek / flehen und wünschen"

çın kèrtü köyülin yalvaru küseyü kşanti ötünü teginürmen (BT 25: 1640) [1 kez]

yayıl- sėzin- "yanılmak ve şüphelenmek / fehlgehen und zweifeln"

ok tilep istep yaylok sakınu muntag yayılurlar sézinürler (BT 25: 0614) [1 kez]

yạılmak sėzik "yanılma ve şüphe / Irrtum und Zweifel”

edgü öglilerke tuşsarlar ol yayılmakları sèzikleri kètar tarıkar (BT 25: 0615) [1 kez]

yaratdur- kıltur- "yarattırmak, kıldırmak, oluşturtmak / zurechtmassen lassen und machen lassen"

yaratdurmış kılturmış erür ( BT 25: 0030) [1 kez]

yarumak yaşumak "parlama, aydınlanma / Leuchten und Glänzen”

etözüm artokrak birkiye yarumak yaşumak üze (...) tüzü tükellig bolup

(BT 25: 3880-3881) [1 kez]

yatgak turgak "bekçi, korucu / nachtwächter und am tage diensttuende aufseher" üküş telim yatgak turgak erenler üze koduru odug sak erip (BT 25: 0056) [1 kez]

yavız kıり "kötü ve kıskanç / böse und scheel"

tülisiz tulvısın yavız kıり köz üze körüp (BT 25: 0772) [1 kez]

yaşlıg üdlüg "yaşlı / der Lebensdauer und der Zeit"

yaşlıg üdlüg luu hanlarl (BT 25: 1764) [1 kez]

yazoksuz 23 bitadı "günahsız, suçsuz, asılsız / unschuldig und grundlos"

kamag adın bek bukagulukta yazoksuz bıtadı solalmış beklelmiş (BT 25: 3121) [1 kez]

yèg küçlüg "mükemmel ve güçlü / vorzüglich und kräftig"

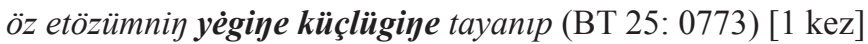

23 Orijinal okuma yoksuz. (Wilkens, 2007:242, 560. dipnot) 
yẻg üstünki edgülüg "çok iyi ve sağlıklı / allerbeste(-r, -s) und heilsame(-r, -s)" yèg üstünki edgülüg tatıglarınıy tatıgların turkaru tatayın (BT 25: 3720) [1 kez]

yèg tözün "en iyi, üstün ve kutsal / besten und edlen" yèg tözün yolka tegmiş (BT 25: 3182) [1 kez]

yẻnik yumşak "hafif ve yumuşak / leicht und weich" üdçe aş aşanmışın yènik yumşak tonlarıg kèterip (BT 25: 0594) [1 kez]

yıglaş- sıgtaş- "ağlaşmak / gemeinsam wehklagen"

kakadaş edgü ögliler tegirmileyü kurşayu yıglaştukda sıgtaştukda ol öldeçi kişi ürküp korkup (BT 25: 2922-2923) [1 kez]

yik yarma "sütun ve mağara / Spalte und Höhle" yme ök yok antag yik yarma tolp etözümin slgurguça (BT 25: 0073-0074) [1 kez]

yilik kan "ilik ve kan / Mark und Blut" tınlıg uguşını yilikiniy kanınıy tatıgın tatmayın (BT 25: 3704) [1 kez]

yip ışıg "ip ve halat / Faden und Schnur"

yip ışıg tartar teg agrig sizlag yorlyur (BT 25: 0566) [1 kez]

yogun èrig24 "kalın, iri, kaba / grob" ulatı yogun èrig savlar üze ère aylglayu (BT 25: 0308) [1 kez]

yorl- bar- "yürümek, varmak / gehen, wandeln" tugmak ölmek sansarlı taloy ügüzüg keçteçilerke yorıuluk barguluk kèmi köprüg boltaçılar üçün (BT 25: 1288-1289) [1 kez]

yorl- tepre- "yürümek, hareket etmek / wandeln und (sich) bewegen" prètlar yorıp teprep (BT 25: 3571)

yumkı barça "topluca, bütün, hepsi / insgesamt" ol kamag tınlıglar yumkı barça ozup kutrulup (BT 25: 0500) [1 kez]

yüküntür- enitdür- "secde ettirmek / zur Verbeugung veranlassen" üç erdinilerke yüküntürelim eyitdürelim (BT 25: 3966-3967) [1 kez]

24 bk. yukarıdaki 8. dipnot. 
yülüg utru "karş1 / gegenüber"

hanka yülüg utru turdı (BT 25: 0051-0052) [1 kez]

yüüz yüzegü "yüz ve diş organlar / Glieder"

yüüz yüzegülerinte barça oot ok tugup (BT 25: 0760) [2 kez]

\section{Sonuç}

Türkçenin en eski yazılı kaynaklarından itibaren görülen ve özellikle Eski Uygurca metinlerde sıkça kullanılan ikilemeler yukarıda anılan çalışmalarda ele alınmakla birlikte, Kşanti Kılguluk Nom Bitig metni üzerine yapılmış son çalışma olan BT 25'te tespit edilen 189 ikilemeye daha önceki yayınlarda yer verilmemiştir. Çalışmada bu ikilemelerin listesi oluşturularak Türkçe ve Almanca karşılıkları ile ikilemenin geçtiği bağlama yer verilmiş, metindeki kullanım sıklığı belirtilmiştir. Giriş bölümünde ikilemeler hakkında yapılan ilk çalışmalardan kısaca bahsedildikten sonra Kşanti Kılguluk Nom Bitig üzerine yazılan çalışmalar hakkında kısa bilgi verilmiştir.

Tespit edilen 189 ikilemeden 72 ikileme fiilden, 117 ikileme ise isimden oluşmaktadır. İkilemelerden 8 ikileme 3 unsurdan oluşmaktadır. Bu ikilemeler; alkugun barça kalısız, buş-

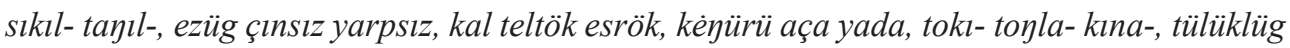
küçlüg küsünlüg ve yèg üstünki edgülüg'dür. 2'den fazla kelimenin görüldüğü fakat aslında 2 unsurdan oluşan ayıg kılınç / buyan, etöz isig / öz, klsur- / kısga kıl-, küse- / kut kolun-, ters nomlug / tirté , edgü ögli / aylg ögli, kal teltök bol- / yayıl-, kut kolunmak / küsüş küsemek, kut kol- / küsüş örit-, taitsoki / ulug agllık nom, ters azag nomlug / tirtè ve ki lug tégme / at bitig ikilemeleri bu tür bir sınıflandırmaya alınmamıştır. İkilemelerden uulsuz/ulsuz tüpsüz alkınçsız tüketinçsiz ise benzer anlamda olan iki ikilemenin sıralanmasıyla oluşan sıralı ikilemedir. $\mathrm{Bu}$ ikilemelerden katıg çike ikilemesinde çike kelimesi ilk kez bu metinde yer almaktadır. Metinde tespit edilen ikilemeler eğer tamamlama ise listeye alınmamış giriş bölümünde belirtilmiştir. İkilemeyi andıran yapılardan bazı örnekler verilmiş, farklı ulaç eki alan ikileme benzeri yapılar da giriş bölümünde aktarılmıştır. Bu çalışma ile şimdiye kadar yukarıda adı geçen eserlerde tespit edilemeyen ikilemeler bir arada verilerek Eski Uygurca söz varlığına katkı hedeflenmiştir. Ayrıca Eski Uygurca metinlerin anlaşılabilirliği ve metin tamiri açısından önemli olan ikilemeler, bu alanda çalışanların bilgisine sunulmuştur. 


\section{Kisaltmalar}

$\begin{array}{ll}\text { BT 25 } & \text { : Wilkens } 2007 \\ \text { DTS } & \text { : Nadelyayev (vd.) } 1969 \\ \text { ED } & \text { : Clauson } 1972 \\ \text { OTWF } & \text { : Erdal 1991 } \\ \text { Skt. } & \text { : Sanskritçe } \\ \text { TDKAlmT } & \text { : Önen ve Şanbey } 1993 \\ \text { UW } & \text { : Röhrborn 1977-1998 } \\ \text { UW NB I.1 } & \text { : Röhrborn 2010 } \\ \text { UW NB II.1 } & \text { : Röhrborn 2015 } \\ \text { UW NB II. 2 } & \text { : Röhrborn } 2017\end{array}$

\section{Kaynaklar}

Ayazlı, Özlem. Eski Uygurca Din Dışı Metinlerin Karşslaştırmalı Söz Varllğı. Ankara: Türk Dil Kurumu, 2016.

Aydemir, Hakan. Untersuchung zum Wortschatz der alttürkischen Xuanzang-Biographie (mit besonderer Berücksichtigung von Buch IX). Yayımlanmamış Yüksek Lisans tezi, Universität Göttingen, 2013.

Clauson, Sir Gerard. An Etymological Dictionary of Pre-Thirteenth-Century Turkish. Oxford: Clarendon Press, 1972.

Çağatay, Saadet. "Uygurca'da Hendiadyoinler”, Dil ve Tarih-Coğrafya Fakültesi Yıllık Çalışmalar Dergisi 1/ 1940-1941 (1944): 97-144. (Türk Lehçeleri Üzerine Denemeler. Ankara, 1978, 29-66'da tekrar yayımlanmıştır.)

Elmalı, Murat. Daśakarmapathāvadānamālā, Giriş-Metin-Çeviri-Notlar-Dizin Tipkıbaskı. Ankara: Türk Dil Kurumu Yayınları, 2016.

Erdal, Marcel. Old Turkic Word Formation: A Functional Approach to the Lexicon, I-II. Wiesbaden: Otto Harrassowitz, 1991.

Foy, Karl. "Studien zur Osmanischen Syntax, das Hendiadyoin und die Wortfolge "ana baba", Mitteilungen des Seminars für Orientalische Sprachen içinde, II. Cilt, 2. bölüm, 105-136, Berlin, 1899.

Hatiboğlu, Vecihe. Türk Dilinde İkileme. Ankara: Türk Dil Kurumu Yayınları, 1981.

Nadelyayev, V. M., D. M. Nasilov, E. R. Tenişev ve A. M. Şçerbak. Drevnetyurkskiy slovar'. Leningrad, 1969.

Ölmez, Mehmet. Altun Yaruk III. Kitap (= 5. Bölüm). Ankara: TDAD 1, 1991.

Ölmez, Mehmet. "Eski Uygurca odug sak İkilemesi Üzerine”, Türk Dilleri Araştırmaları, 8 (1998): 35-47.

Ölmez, Mehmet. “Eski Uygurca İkilemeler Üzerine”, Türk Dili Araştırmaları Yıllı̆̆l - Belleten, 65/ 2 (2017): 243-311.

Ölmez, Mehmet. "ON OLD UYGUR Sıkıg Sıkış AND Tạıg Tạış”, Z. Gulácsi (ed.) Language, Society, and Religion in the World of the Turks Festschrift for Larry Clark at Seventy-Five içinde, 89-98. Turnhout: Brepols Publishers, 2018.

Önen, Yaşar ve Cemil Ziya Şanbey. Almanca - Türkçe Sözlük (Cilt I-II). Ankara: Türk Dil Kurumu, 1993.

Pott, A. F., Doppelung (Reduplikation, Gemination) als eines der wichtigsten Bildungsmittel der Sprache: beleuchtet aus Sprachen aller Welttheile. Lemgo Germany: Im Verlage der Meyer'schen Hofbuchhandlung, 1862. 
Röhrborn, Klaus. Eine uigurische Totenmesse. Text, Übersetzung, Kommentar. Berlin: Akademie Verlag, 1971.

Röhrborn, Klaus. Uigurisches Wörterbuch. Sprachmaterial der vorislamischen türkischen Texte aus Zentralasien. 1-6. Wiesbaden: Franz Steiner Verlag, 1977-1998.

Röhrborn, Klaus. Uigurisches Wörterbuch. Sprachmaterial der vorislamischen türkischen Texte aus Zentralasien, - Neubearbeitung - I. Verben. Band 1: ab- - äzüglä-. Stuttgart: Franz Steiner Verlag, 2010.

Röhrborn, Klaus. Uigurisches Wörterbuch. Sprachmaterial der vorislamischen türkischen Texte aus Zentralasien, - Neubearbeitung - II. Nomina-Pronomina-Partikeln. Band 1: a-asvı. Stuttgart: Franz Steiner Verlag, 2015.

Röhrborn, Klaus. Uigurisches Wörterbuch. Sprachmaterial der vorislamischen türkischen Texte aus Zentralasien, - Neubearbeitung - II. Nomina-Pronomina-Partikeln. Band 2: aş-äz̈ük. Stuttgart: Franz Steiner Verlag, 2017.

Şen, Serkan. “Eski Uygur Türkçesinde İkilemeler”. Yüksek Lisans tezi, Ondokuz Mayıs Üniversitesi, 2002.

Warnke, Ingrid. Eine buddhistische Lehrschrift über das Bekennen der Sünden, Fragmente der uigurischen Version des Cibei-daochang-chanfa. Doktora tezi, Berlin, Bilimler Akademisi, 1978.

Warnke, Ingrid. "Fragmente des 25. und 26. Kapitels des Kšanti qïlyuluq nom bitig”, Altorientalische Forschungen, 10(1-2), (1983): 243-268.

Wilkens, Jens. Das Buch von der Sündentilgung. Edition des alttürkisch-buddhistischen Kšanti Kllguluk Nom Bitig (Cilt I-II). Turnhout, Belgium: Brepols Publishers, 2007. 